\title{
THE INFLUENCE OF DEXMEDETOMIDINE ON SODIUM NITROPRUSSIDE INDUCED HYPOTENSION DURING ISOFLURANE ANAESTHESIA
}

AUTHORS: Mounis A. Abosedira FFFARCSI, FRCA, Hany A. Mowafi MD, Hosam H. Elsabae MD

AFFILIATION: King Faisal University, Al-Dammam, Saudi Arabia.

INTRODUCTION: Induced hypotension using sodium nitroprusside (SNP) is associated with reflex tachycardia, tachyphylaxis \& the risk of cyanide toxicity [ ] Dexmedetomidine, a selective $2^{-}$ adrenoceptor agonist, produces a dose-dependent decrease in blood pressure and heart rate suggesting that it would be a useful adjuvant to SNP deliberate hypotension [ $\&$.This randomised, double blind \& placebo controlled study was designed to investigate the influence of dexmedetomidine on SNP requirement for deliberate hypotension.

METHODS: Thirty patients scheduled for elective body surface surgery were included in the study after the Local Ethics Committee \& informed patient consent was obtained. After the institution of routine monitoring, one radial artery was cannulated $(20 \mathrm{G})$ for direct blood pressure measurement. Patients were allocated randomly to receive $20 \mathrm{ml}$ of either saline or dexmedetomidine $\left(1 \mu \mathrm{g} \cdot \mathrm{kg}^{-1} \mathrm{in}\right.$ saline) ; by intravenous infusion over 20 minutes, prior to induction. Anaesthesia was induced using morphine $\left(0.1 \mathrm{mg} \cdot \mathrm{kg}^{-1}\right)$ propofol $\left(1-2 \mathrm{mg} \cdot \mathrm{kg}^{-1}\right)$ and cis-atracurium $\left(0.15 \mathrm{mg} \cdot \mathrm{kg}^{-1}\right)$. Anaesthesia was maintained with $0.8 \%$ end-tidal isoflurane concentration in $50 \% \mathrm{~N}_{2} \mathrm{O}$ in $\mathrm{O}_{2}$ and incremental cisatracurium. Once surgery started, SNP infusion was started $\&$ the rate adjusted to maintain mean arterial pressure (MAP) between $60-65 \mathrm{mmHg}$. The hear rate (HR) was recorded before, during steady-state SNP infusion \& every 5 minutes after stopping SNP.

RESULTS: The patients' demographic data, duration of surgery \& duration of hypotension did not show statistically significant differences. The results are summarized in table 1.

Table 1. The SNP requirement and hemodynamic variables. Data are presented as mean values (SD) unless otherwise indicated. SNP: sodium nitroprusside.

\begin{tabular}{|lc|c|c|c|}
\hline & & Control $\mathbf{N = 1 5})$ & Dex $(\mathbf{N = 1 5})$ & P -value \\
\hline SNP omitted & $(\%)$ & $1(6.7 \%)$ & $5 *(33.3 \%)$ & $<0.05$ \\
\hline SNP consumption & $\mathbf{( m g )}$ & $5.8(2.3)$ & $1.78 *(1.8)$ & $<0.05$ \\
\hline SNP rate & $\left(\boldsymbol{\mu g . k g}^{-1} \mathbf{m i n}^{-1}\right)$ & 1.15 & $0.41 *$ & $>0.05$ \\
\hline HR pre-SNP & $\mathbf{( B / m i n )}$ & $67.3(9.3)$ & $72.2(8.3)$ & $>0.05$ \\
\hline HR s.state -SNP & $\mathbf{( B / m i n )}$ & $70.2(7.8)$ & $72.1(14)$ & $>0.05$ \\
\hline HR post-SNP & $\mathbf{( B / m i n )}$ & $65(5.9)$ & $67.8(11.9)$ & $>0.05$ \\
\hline MAP pre-SNP & $\mathbf{( m m H g )}$ & $77(8.2)$ & $74.7(3.2)$ & $>0.05$ \\
\hline MAP steady-state & $\mathbf{( m m H g )}$ & $62.3(1.3)$ & $63(1.1)$ & $>0.05$ \\
\hline MAP 5min post-SNP & $\mathbf{( m m H g )}$ & $76.8(9.9)$ & $77.2(7.5)$ & $>0.05$ \\
\hline
\end{tabular}

DISCUSSION: The results of this study reveal that Dexmedetomidine in a single intravenous dose (1 $\mu \mathrm{g} / \mathrm{kg}$ ) may obviate the need for SNP, reduce the SNP dose requirement by $64.3 \%$ without delaying the rate of recovery of MAP upon SNP withdrawal \& is a safe adjuvant to SNP for induced hypotension under isoflurane anaesthesia. Direct comparison of dexmedetomidine-SNP combination versus other combinations are needed. Dexmedetomidine as a sole agent for deliberate hypotension should be studied.

\section{REFERENCES:}

[ ] Anaesthesia and Intensive Care 1994; 22: 155-60

[ \&BJA 1997; 78: 400-6 